\title{
Effects of sample size, centrifugal acceleration and brine inclusions on the elastic modulus of sea ice
}

\author{
Michael LAU, ${ }^{1}$ Stephen J. JONES, ${ }^{1}$ Ryan PHILLIPS ${ }^{2}$ \\ ${ }^{1}$ Institute for Ocean Technology, National Research Council of Canada, PO Box 12093, St John's, \\ Newfoundland A1B 3T5, Canada \\ E-mail: Michael.Lau@nrc.ca \\ ${ }^{2}$ C-CORE, Memorial University of Newfoundland, St John's, Newfoundland A1B 3X5, Canada
}

\begin{abstract}
We present a re-analysis of the results obtained from a series of measurements on freshwater and saline ice beams under various centrifugal accelerations. The data show a strong influence of beam size, brine volume and centrifugal acceleration on the elastic modulus of ice. The data suggest a transition brine volume at around $9 \%$, which might occur close to the melting point, at which the elastic modulus of ice drops rapidly due to a possible change of brine-pocket structure. Furthermore, for brine volumes less than $9 \%$, there is a negligible increase in the elastic modulus measured under high centrifugal acceleration, but for brine volumes more than $9 \%$ the increase is considerable, approaching that measured with freshwater ice. This may be due to necking of brine drainage channels just above the ice/water interface at high centrifugal acceleration. A model of sea ice was constructed based on existing theories of brine inclusions in sea ice, which satisfactorily predicts the observed trends.
\end{abstract}

\section{INTRODUCTION}

Centrifuge modeling has become a powerful and versatile tool for the geotechnical engineer. It was originally applied to the solution of classical problems in slope stability theory, but its applications have now expanded to cover many diverse areas, among them dynamic response to earthquakes, diffusion of heat and chemical pollutants, soilstructure interaction, marine geotechnics and permafrost. A number of workers have applied the method to ice (Clough and Vinson, 1986a, b; Lovell and Schofield, 1986; Langhorne and others, 1999). We plan to apply the method to sea-ice interactions and begin by studying the mechanical properties of sea ice under acceleration. This paper concerns the elastic modulus ( $E$-modulus, $E$ ) of sea ice. The $E$-modulus of sea ice is important in many aspects of ice engineering. A literature review by Gagnon and Jones (2001) summarized work on the elastic properties of all forms of ice. Gagnon and Jones showed that the true $E$-modulus must be measured at high frequencies because of the ability of sea ice to creep, even at very low stresses. At high frequencies, the dynamic $E$-modulus of sea ice decreases with increasing brine volume from $\sim 10 \mathrm{GPa}$, the value obtained for freshwater ice. At static, or low frequencies, the dynamic the

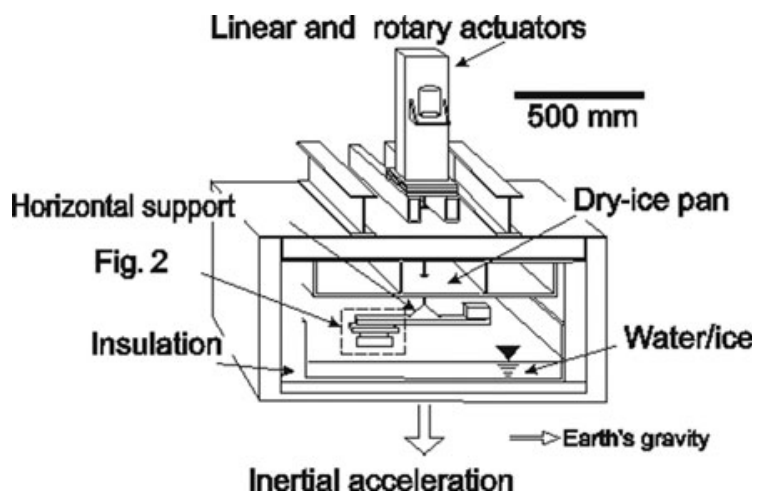

Fig. 1. Sectional view of test package (Barrette and others, 1998a).
$E$-modulus depends on brine volume, loading rate, temperature and orientation; at $-10^{\circ} \mathrm{C}$ and a salinity of $5 \%$, it has a value in the range 3-5 GPa. Experimental data have shown a large reduction of $E$-modulus of ice with increasing brine volume (Weeks and Assur, 1967).

In this paper, we present a re-analysis of the results obtained from a series of measurements on small freshwater and saline ice beams under various centrifugal accelerations. A model of sea ice is presented based on existing theories of brine inclusions in sea ice, which qualitatively predicts the observed trends well.

\section{CENTRIFUGE MODELING OF ICE PROBLEMS}

Centrifuge modeling involves the simulation of a given phenomenon that is reduced in size by a scale factor, $n$, under an artificially imposed, inertial acceleration $n$ times that of Earth's gravity, so that gravity-induced stresses in the model correctly reflect those in the prototype (Schofield, 1980; Murff, 1996). A significant advantage with centrifuge modeling in ice-related problems is that modification of the mechanical properties of ice (routinely done in large refrigerated tanks) is, in principle, not required. As a result, the mechanical properties of the model are more representative of the prototype when compared to those presently achieved with artificial model ice (Barrette and others, 1999; Lau and others, 2001). Due to the small size of the model required, centrifuge modeling also has the advantage of simulating and maintaining a small controlled test environment for a fraction of the cost of a conventional ice tank. Furthermore, standard test techniques can be adapted to the centrifuge test environment. For example, the static (or effective) elastic moduli presented in this paper were measured using the standardized testing method for ice, recommended by Schwarz and others (1981).

\section{THE EXPERIMENT AND THE DATASET}

Our re-analysis is based on measurements reported by Barrette and others $(1997,1998 a)$ on freshwater ice and 


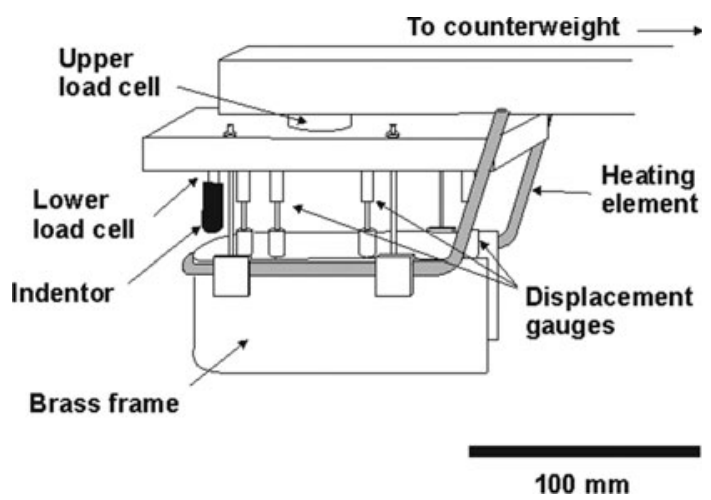

Fig. 2. Schematic diagram of instrumentation used to perform in situ cantilever beam tests (Barrette and others, 1998a). The brass frame (U-shaped) is indicated.

Barrette and others (1999) on saline ice. Tables 1 and 2 summarize the test data from these publications. Barrette and others' tests were carried out at the C-CORE centrifuge facility through the in situ production and indentation of cantilever beams at inertial accelerations equivalent to 1 , 12.5, 25 and 50 times the Earth's gravitational acceleration (hereafter abbreviated to $1 \mathrm{~g}, 12.5 \mathrm{~g}, 25 \mathrm{~g}$ and $50 \mathrm{~g}$, respectively). A thermally insulated water basin with surface dimensions $1030 \mathrm{~mm} \times 790 \mathrm{~mm}$ was housed in a standard containment structure for centrifuge flights (Fig. 1). The lid of this box was composed of an insulated-pan assembly suspended above a water basin, in which dry ice was distributed equally.

The ice was grown through frost nucleating on the lower surface of the dry-ice pan and precipitating onto the water/ ice surface, followed by one-dimensional directional freezing resulting in columnar-grained S2 ice, while the centrifuge was at rest or in flight at simulated gravity. Temperature at the air/ice interface varied between -10 and $-1^{\circ} \mathrm{C}$. The lower temperatures were observed at higher inertial accelerations, with a consequent increase in growth rate. A prior study (Barrette and others, 1998b) of the physical properties of saline ice produced at high inertial acceleration concluded that inertial acceleration did not affect the crystal size and that the laboratory-prepared columnar-grained ice was a correctly scaled-down version of natural columnar ice. A U-shaped brass frame (Fig. 2) was used to cut the beams, $100 \mathrm{~mm} \times 34 \mathrm{~mm}$, directly from the ice cover. The thickness of the ice cover ranged from 11 to $23 \mathrm{~mm}$, and the beam thickness was, on average, $17 \pm 6 \mathrm{~mm}$. This yields an average dimension ratio of $\sim 1: 2: 6$ (thickness: width: length). The salinity of the cantilever beams ranged from $0.08 \%$ to $4.0 \%$, with the corresponding brine volume ranging from $1.1 \%$ to $66.8 \%$.

The load was applied to the free end of the ice beam at rates ranging from 0.6 to $3 \mathrm{~mm} \mathrm{~s}^{-1}$ until beam failure. The beam deflections at four locations along its length were recorded during indentation. The effective modulus was calculated based on the vertical displacement measured at the four locations along the beam using a least-squares regression analysis. The buoyancy-induced resistance was estimated and subtracted from the measured indentation forces. Time to beam failure for all tests was consistent, within $1 \mathrm{~s}$, with the recommendations of Schwarz and others (1981). Barrette and others (1998a, 1999) found no evidence from these test data that loading rate has any influence on E-modulus.

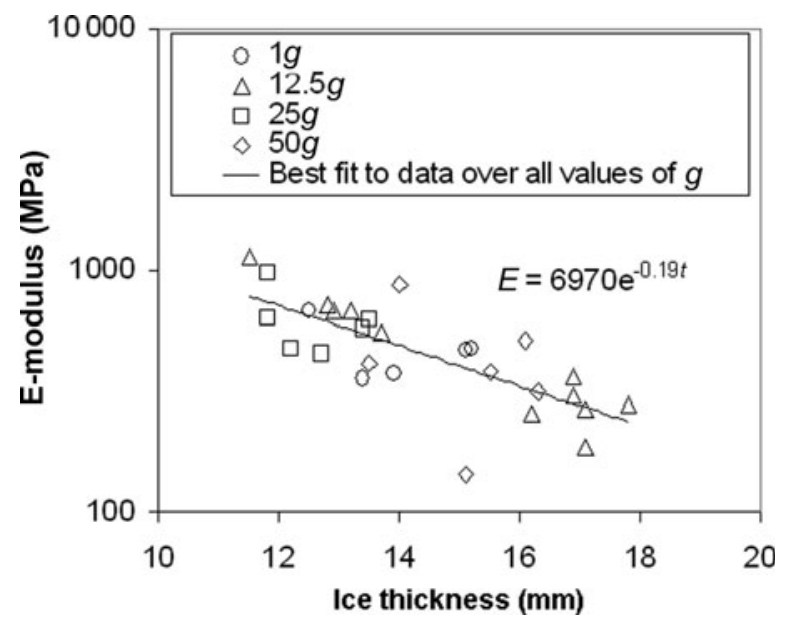

Fig. 3. E-modulus versus ice thickness, $t$, for freshwater ice at different simulated accelerations (Barrette and others, 1997, 1998a), along with a regression line through all data.

\section{SIZE EFFECTS}

An apparent size effect on flexural strength, as exhibited in prototype ice, was observed in C-CORE's ice. By this we mean that the value of the flexural strength of the ice beams depended on the size of the test specimen. Some workers have noticed this in natural sea ice (Parsons and others, 1992). The experimental evidence of this size effect was given by Lau and others (2001), based on measurements on small freshwater and saline ice beams. A scaling method to account for this effect has been developed and documented (Lau and others, 2001).

A review of Barrette and others' (1997, 1998b, 1999) beam data showed sample size, specifically beam thickness, had a strong influence on the measured values of $E$-modulus. This obscured the relationship between $E$-modulus, brine volume and centrifugal acceleration in the previous analysis. In this paper, the modulus values are re-examined taking the influence of beam size into account.

\section{Freshwater ice tested at different acceleration levels}

Figure 3 shows the effect of ice thickness on the $E$-modulus, $E$, of freshwater ice for different centrifugal accelerations, $1 g$, $12.5 \mathrm{~g}, 25 \mathrm{~g}$ and $50 \mathrm{~g}$. There is a strong influence of sample size on E-modulus, but no discernible influence of centrifugal acceleration is observed. The large scatter in the data reported previously with the freshwater ice is mainly due to the wide range of beam thickness used in the tests. The relationship,

$$
E=6970 \mathrm{e}^{-k t}
$$

best fits the data at all acceleration levels, where $E$ is expressed in $\mathrm{MPa}, t$ is ice thickness in millimeters and $k$ is equal to 0.19. Equation (1) describes the size influence on $E$ for a freshwater-ice beam and is referred to as the 'freshwater limit' in this paper.

All $E$ values shown in Figure 3 are significantly lower than the value of $3-5 \mathrm{GPa}$ for low frequencies at $-10^{\circ} \mathrm{C}$ and $5 \%$ salinity (Gagnon and Jones, 2001). We believe this is due principally to the high temperature of the tests, as most of the data were collected at $-0.2^{\circ} \mathrm{C}$. The small size of the beams may also have been a factor. 
Table 1. Summary of test data on saline ice reported by Barrette and others (1999)

Test No. $\quad$ Average ice temp. Bulk ice salinity Brine vol. fraction Ice thickness $\quad$ Flexural strength $\quad$ Elastic modulus

$\begin{array}{lllll}{ }^{\circ} \mathrm{C} & \% & \mathrm{~mm} & \mathrm{MPa} & \mathrm{MPa}\end{array}$

Dry beams - growth $1 g$, test $1 g$ (sheet 1$)$

6325

6355

6375

6395

$-0.3$

$-0.3$

$-0.3$

Dry beams - growth $1 g$, test $1 g$ (sheet 2)

$\begin{array}{ll}6301 & -16.3 \\ 6302 & -16.4 \\ 6303 & -16.4 \\ 6304 & -16.5\end{array}$

Dry beams - growth $1 g$, test $1 g$ (sheet 3 )

6305
6306

6307

$-10.6$

$-10.5$

$-10.4$

Floating beams - growth $1 \mathrm{~g}$, test $1 \mathrm{~g}$ (sheet 4$)$

$\begin{array}{ll}6309 & -6.3 \\ 6310 & -6.3 \\ 6311 & -6.3 \\ 6312 & -6.3\end{array}$

Dry beams - growth $1 g$, test $1 g$ (sheet 5 )

$\begin{array}{ll}6313 & -1.8 \\ 6314 & -1.8 \\ 6315 & -1.8 \\ 6316 & -1.8\end{array}$

Floating beams - growth $1 g$, test $1 g$ (sheet 6)

$\begin{array}{ll}6401 & -0.2 \\ 6402 & -0.2 \\ 6403 & -0.2 \\ 6404 & -0.2 \\ 6405 & -0.2 \\ 6406 & -0.2\end{array}$

Floating beams - growth $1 g$, test $1 g$ (sheet 7)

$\begin{array}{ll}6501 & -0.2 \\ 6502 & -0.2 \\ 6503 & -0.2 \\ 6504 & -0.2\end{array}$

Floating beams - growth $1 g$, test $1 g$ (sheet 8 )

$\begin{array}{ll}6601 & -0.2 \\ 6602 & -0.2 \\ 6603 & -0.2 \\ 6604 & -0.2 \\ 6605 & -0.2 \\ 6606 & -0.2\end{array}$

Floating beams - growth $1 g$, test $25 \mathrm{~g}$ (sheet 9)

$\begin{array}{ll}6701 & -0.2 \\ 6702 & -0.2 \\ 6703 & -0.2 \\ 6704 & -0.2\end{array}$

Floating beams - growth $25 \mathrm{~g}$, test $12.5 \mathrm{~g}$ (sheet 10 )

$\begin{array}{ll}6705 & -0.2 \\ 6706 & -0.2 \\ 6707 & -0.2 \\ 6708 & -0.2\end{array}$

Floating beams - growth $50 \mathrm{~g}$, test $12.5 \mathrm{~g}$ (sheet 11 )

$\begin{array}{lll}6801 & -0.2 & 0.56 \\ 6802 & -0.2 & 0.51 \\ 6803 & -0.2 & 0.32 \\ 6804 & -0.2 & 0.34 \\ 6805 & -0.2 & 0.51\end{array}$

0.668
0.668
0.668
0.668

0.012

0.012

0.012

0.011

0.015

0.017

0.017

0.027

0.025

0.025

0.016

0.054

0.081

0.054

0.054

0.78

0.71

0.194

0.178

0.190

0.143

0.188

0.194

\subsection{8}

0.78

0.66

0.66

0.196

0.196

0.165

0.165

2.08

2.08

2.09

2.21

1.99

2.23

0.520

0.520

0.522

0.553

0.496

0.559

0.64

0.75

0.45

0.59

0.159

0.188

0.114

0.147

\subsection{8}

0.54

0.65

0.64

0.121

0.135

0.163

0.160

0.141

0.128

0.081

0.084

0.127

15
16
18
17

0.03

0.01

0.02

0.02

3.0

2.7

1.9

2.7

$\begin{array}{rr}1.18 & 67.8 \\ 1.42 & 263.3 \\ 1.44 & 155.4 \\ 1.23 & 210.0\end{array}$

1.30

1.36

206.0

20
20

20

1.24

191.2

215.9

0.90

0.90
1.44

187.7

$1.31 \quad 136.5$

$\begin{array}{ll}0.86 & 175.4\end{array}$

$\begin{array}{ll}0.58 & 127.4\end{array}$

$0.57 \quad 109.2$
0.87

$\begin{array}{ll}0.87 & 162.1\end{array}$

$0.67 \quad 257.8$

$0.09 \quad 27.1$

$\begin{array}{ll}0.09 & 54.7\end{array}$

N/A $\quad 37.8$

$0.11 \quad 28.1$

$0.11 \quad 27.7$

$\begin{array}{ll}0.11 & 22.5\end{array}$

$0.11 \quad 50.3$

$0.13 \quad 23.8$

$0.10 \quad 36.2$

$\begin{array}{ll}0.16 & 58.0\end{array}$

$\begin{array}{ll}0.05 & 7.1\end{array}$

$0.05 \quad 13.5$

$\begin{array}{ll}0.06 & 10.0\end{array}$

$0.06 \quad 12.1$

$0.09 \quad 15.8$

$0.07 \quad 13.0$

$0.39 \quad 184.8$

$0.30 \quad 455.2$

$0.33 \quad 343.7$

$0.32 \quad 374.7$

$0.22 \quad 256.1$

$0.26 \quad 232.5$

$0.23 \quad 131.2$

$0.23 \quad 266.0$

$\begin{array}{lll}23 & 0.23 & 266.0\end{array}$

$0.47 \quad 240.1$

$0.44 \quad 121.0$

$0.64 \quad 387.0$

$0.61 \quad 364.6$

$0.29 \quad 174.2$ 
Table 1. (continued)

\begin{tabular}{|c|c|c|c|c|c|c|}
\hline Test No. & $\begin{array}{l}\text { Average ice temp. } \\
{ }^{\circ} \mathrm{C}\end{array}$ & $\begin{array}{l}\text { Bulk ice salinity } \\
\qquad \%\end{array}$ & Brine vol. fraction & $\begin{array}{l}\text { Ice thickness } \\
\qquad \mathrm{mm}\end{array}$ & $\begin{array}{l}\text { Flexural strength } \\
\qquad \mathrm{MPa}\end{array}$ & $\begin{array}{c}\text { Elastic modulus } \\
\qquad \mathrm{MPa}\end{array}$ \\
\hline \multicolumn{7}{|c|}{ Floating beams - growth $50 g$, test $50 g$ (sheet 12 ) } \\
\hline 6901 & -0.2 & 0.13 & 0.034 & 14 & 1.07 & 1179.1 \\
\hline 6902 & -0.2 & 0.14 & 0.036 & 15 & 0.84 & 954.9 \\
\hline 6903 & -0.2 & 0.14 & 0.034 & 14 & 1.20 & 433.0 \\
\hline 6904 & -0.2 & 0.11 & 0.028 & 15 & 0.85 & 581.0 \\
\hline \multicolumn{7}{|c|}{ Floating beams - growth $50 g$, test $25 g$ (sheet 13 ) } \\
\hline 7001 & -0.2 & 0.27 & 0.067 & 13 & 0.66 & 821.5 \\
\hline 7002 & -0.2 & 0.20 & 0.051 & 14 & 0.80 & 792.2 \\
\hline 7003 & -0.2 & 0.14 & 0.035 & 13 & 0.72 & 664.0 \\
\hline \multicolumn{7}{|c|}{ Floating beams - growth $50 \mathrm{~g}$, test $12.5 \mathrm{~g}$ (sheet 14 ) } \\
\hline $704 \quad 0$ & -0.2 & 0.17 & 0.042 & 17 & 0.63 & 413.8 \\
\hline 705 & -0.2 & 0.22 & 0.055 & 17 & 0.70 & 411.0 \\
\hline 706 & -0.2 & 0.21 & 0.051 & 18 & 0.54 & 375.4 \\
\hline \multicolumn{7}{|c|}{ Floating beams - growth $50 g$, test $1 g$ (sheet 15$)$} \\
\hline 7007 & -0.2 & 0.19 & 0.046 & 19 & 0.56 & 129.0 \\
\hline 7008 & -0.2 & 0.19 & 0.048 & 18 & 0.53 & 273.0 \\
\hline 7009 & -0.2 & 0.20 & 0.049 & 18 & 0.45 & 269.0 \\
\hline \multicolumn{7}{|c|}{ Floating beams - growth $50 g$, test $25 g$ (sheet 16 ) } \\
\hline 7101 & -0.2 & 0.10 & 0.026 & 12 & 0.76 & 1236.1 \\
\hline 7102 & -0.2 & 0.08 & 0.019 & 12 & 1.05 & 989.0 \\
\hline 7103 & -0.2 & 0.10 & 0.026 & 12 & 0.80 & 1063.5 \\
\hline 7104 & -0.2 & 0.13 & 0.031 & 13 & 0.89 & 1295.3 \\
\hline \multicolumn{7}{|c|}{ Floating beams - growth $50 g$, test $50 g$ (sheet 17 ) } \\
\hline 7105 & -0.2 & 0.13 & 0.033 & 13 & 0.80 & 666.2 \\
\hline 7106 & -0.2 & 0.12 & 0.031 & 13 & 0.79 & 1401.5 \\
\hline \multicolumn{7}{|c|}{ Floating beams - growth $50 g$, test $1 g$ (sheet 18 ) } \\
\hline 7107 & -0.2 & 0.08 & 0.019 & 14 & 0.83 & 262.0 \\
\hline 7108 & -0.2 & 0.13 & 0.032 & 15 & 0.88 & 249.0 \\
\hline 7109 & -0.2 & 0.10 & 0.024 & 16 & 0.88 & 333.0 \\
\hline
\end{tabular}

\section{Saline ice tested at Earth's gravity}

Figure 4 shows the effect of ice thickness on $E$-modulus for saline ice at $1 g$. The data were grouped according to their brine volumes. Again, size had a strong influence on the $E$-modulus. Furthermore, for $v_{\mathrm{b}}^{1 / 2} \leq 0.28$, where $v_{\mathrm{b}}$ is the brine volume, the data show negligible influence of brine volume on the modulus. This observation justifies the fitting of all data with $v_{\mathrm{b}}^{1 / 2} \leq 0.28$ as one group. Best fits to this and other brine-volume data groups are shown in Figure 4. The lines are almost parallel to each other, indicating a similar modulus-sample-size relationship for each brine-volume group. For $1 g$ tests, the relation

$$
E=f\left(v_{b}^{1 / 2}\right) \mathrm{e}^{-k t}
$$

is proposed to describe the E-modulus to sample-size relationship for different brine volumes, where $f\left(v_{\mathrm{b}}^{1 / 2}\right)$ is a function of brine volume and $k$ ranges from 0.13 to 0.19 .

\section{BRINE-VOLUME EFFECT}

Since most beams were tested at a thickness close to $17.5 \mathrm{~mm}$, it is possible to examine the effect of brine volume on $E$ at that thickness. The value of $E$ at $t=17.5 \mathrm{~mm}$ for each brine-volume group obtained at $1 \mathrm{~g}$ was computed from the appropriate best-fit curve and plotted against $v_{b}^{1 / 2}$ in Figure 5. Best fits to the data resulted in the relationships,

$$
E_{t=17.5}=-7.53 v_{\mathrm{b}}^{1 / 2}+242
$$

for $v_{\mathrm{b}}^{1 / 2}<0.3$, and

$$
E_{t=17.5}=1.90\left(v_{\mathrm{b}}^{1 / 2}\right)^{-3.7}
$$

for $v_{\mathrm{b}}^{1 / 2} \geq 0.3$

The data suggest a transition at $v_{\mathrm{b}}^{1 / 2} \sim 0.3$, i.e. a $v_{\mathrm{b}}$ value around $9 \%$. This is consistent with the percolation threshold of $5-7 \%\left(v_{b}^{1 / 2}=0.22-0.26\right)$ below which gravity drainage stops altogether, as suggested by laboratory and field evidence (Weeks and Ackley, 1986; Golden and others, 1998; Golden, 2001). This transition may be attributed to a change of brine-pocket structure from an unconnected to a connected system as illustrated by Golden (2001) and is discussed later. At $v_{b}^{1 / 2}<0.3$, brine volume has an insignificant effect. At the transition point, the $E$-value drops rapidly and the beam loses most of its stiffness.

\section{CENTRIFUGAL ACCELERATION EFFECT}

There was no discernible influence of centrifugal acceleration on the $E$-modulus for the freshwater ice. For saline ice, 


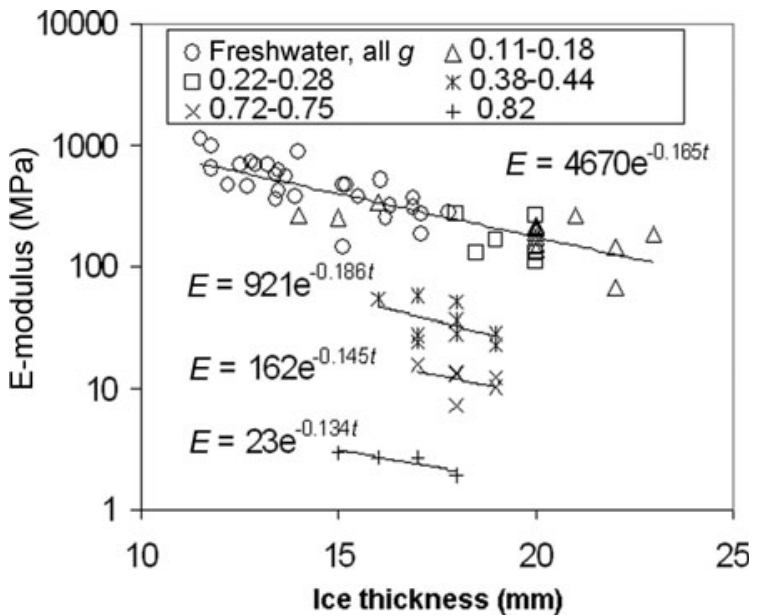

Fig. 4. E-modulus versus ice thickness, $t$, for saline ice at $1 g$ and freshwater ice at different accelerations. Data are grouped according to indicated ranges of values of $v_{b}^{1 / 2}$ (Barrette and others, 1997, 1998a, 1999). Separate regression lines are shown through the three highest salinity ranges, while one regression line suffices for the two lowest $v_{b}^{1 / 2}$ groups and the freshwater ice.

Table 2. Summary of test data on freshwater ice reported by Barrette and others $(1997,1998 \mathrm{a})$

\begin{tabular}{ccc}
\hline Test No. & Ice thickness \\
$\mathrm{mm}$ & Flexural strength & Elastic modulus \\
& $\mathrm{MPa}$ & $\mathrm{MPa}$ \\
\hline
\end{tabular}

$\begin{array}{lccc}\text { Floating beams - growth } 1 g \text {, test } 1 g & & \\ 4801 & 12.5 & 1.68 & 675 \\ 4802 & 13.4 & 1.69 & 360 \\ 4803 & 15.1 & 1.23 & 466 \\ 4804 & 13.9 & 1.14 & 376 \\ 4805 & 15.2 & 0.46 & 472\end{array}$

Floating beams - growth $25 \mathrm{~g}$, test $25 \mathrm{~g}$

$\begin{array}{llll}5101 & 11.8 & 0.70 & 632 \\ 5102 & 13.4 & 0.97 & 568 \\ 5103 & 12.7 & 0.86 & 453 \\ 5104 & 13.5 & 0.70 & 629 \\ 5105 & 12.2 & 0.86 & 472 \\ 5106 & 11.8 & 0.80 & 976\end{array}$

Floating beams - growth $50 \mathrm{~g}$, test $50 \mathrm{~g}$

$\begin{array}{llll}5201 & 14 & 0.79 & 871 \\ 5202 & 13.5 & 0.72 & 412 \\ 5203 & 16.1 & 0.45 & 515 \\ 5204 & 15.5 & 0.85 & 383 \\ 5205 & 15.1 & 0.77 & 144 \\ 5206 & 16.3 & 0.92 & 317\end{array}$

Floating beams - growth $12.5 \mathrm{~g}$, test $12.5 \mathrm{~g}$

$\begin{array}{lllr}5301 & 13.2 & 0.89 & 683 \\ 5302 & 12.8 & 1.00 & 720 \\ 5303 & 12.9 & 0.92 & 679 \\ 5304 & 13.7 & 0.50 & 554 \\ 5305 & 11.5 & 0.84 & 1127 \\ 5306 & 17.1 & 1.06 & 187 \\ 5307 & 17.1 & 1.11 & 265 \\ 5308 & 16.2 & 1.23 & 256 \\ 5309 & 16.9 & 1.09 & 306 \\ 5310 & 16.9 & 0.67 & 366 \\ 5311 & 17.8 & 1.00 & 281\end{array}$

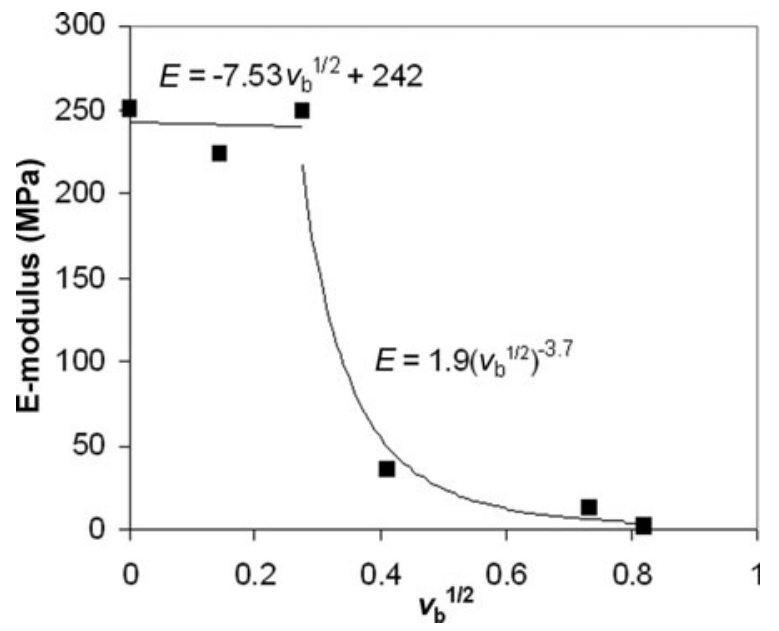

Fig. 5. $E$-modulus versus $v_{b}^{1 / 2}$, as shown by Barrette and others' data. $E$-modulus values have been adjusted to an ice thickness, $t=17.5 \mathrm{~mm}$. There is little effect on $E$-modulus of $v_{\mathrm{b}}^{1 / 2}<0.3$, but a rapid reduction of $E$-modulus with increasing $v_{b}^{1 / 2}>0.3$.

the data show different degrees of influence of centrifugal acceleration on the $E$-value below and above the brinevolume transition point.

\section{Saline ice with $v_{b}^{1 / 2}<0.3$ tested at different acceleration levels}

Figure 6 shows the dependency of $E$-modulus of saline ice on beam thickness for $v_{b}^{1 / 2} \leq 0.3$ at different acceleration levels. The freshwater limit is also plotted. The following trends are evident:

The dataset obtained at $1 g$ shows no discernible deviation from the freshwater limit.

The dataset for $12.5 \mathrm{~g}$ shows an increase of $E$ by $43 \%$, $\sim 90 \mathrm{MPa}$ (on average), over that predicted by the freshwater limit for the same thickness.

Datasets for both $25 \mathrm{~g}$ and $50 \mathrm{~g}$ show an increase in $E$ of $\sim 60 \%, \sim 300 \mathrm{MPa}$ (on average), over that predicted by the freshwater limit for the same thickness, and there is no further increase in $E$ beyond $25 \mathrm{~g}$.

When the beam size is taken into account, the increase in $E$ due to centrifugal acceleration is substantially less than previously reported by Barrette and others (1999). The data also suggest an acceleration threshold beyond which the modulus no longer increases.

\section{Saline ice with $v_{b}^{1 / 2}>0.3$ tested at different acceleration levels}

Figure 7 shows the dependence of the $E$-modulus of saline ice on beam thickness for $v_{b}^{1 / 2}$ over the range 0.34-0.44, at different accelerations. Again, the freshwater limit is plotted in the figure. Despite the limited amount of data, they show an increase in $E$-modulus by as much as $200 \mathrm{MPa}$, at $12.5 \mathrm{~g}$ and $25 \mathrm{~g}$, over those of similar salinity obtained at $1 \mathrm{~g}$. Thicker ice beams, tested at $12.5 \mathrm{~g}$, experienced a greater increase in $E$-modulus than the thinner beams tested at the higher acceleration of $25 \mathrm{~g}$. At these higher salinities, i.e. $v_{\mathrm{b}}^{1 / 2}>0.3$, the values of $E$ at both acceleration levels, $12.5 \mathrm{~g}$ and $25 \mathrm{~g}$, were close to the freshwater limit. 


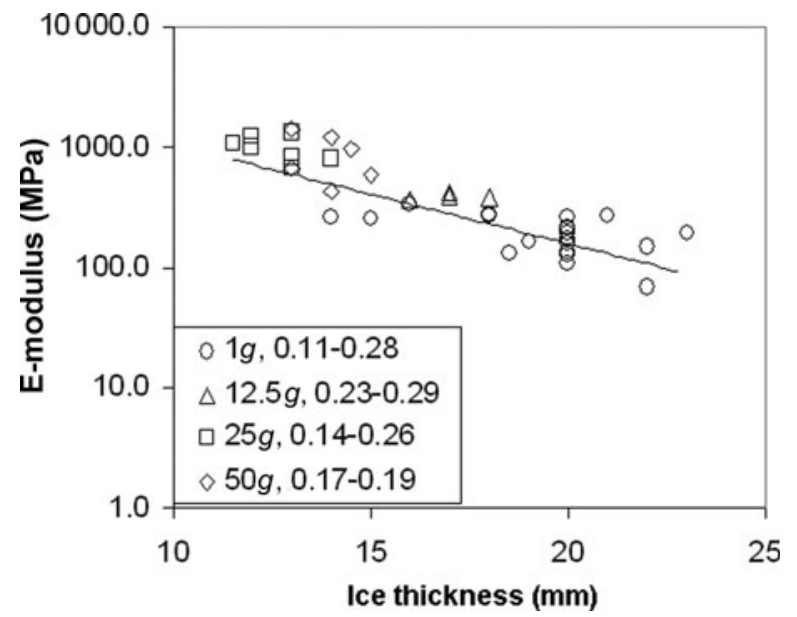

Fig. 6. E-modulus versus ice thickness, $t$, showing little difference in the data for different accelerations (i.e. negligible effect of acceleration on $E$ ), for ice with $v_{\mathrm{b}}^{1 / 2}<0.3$ (for actual values see key). The freshwater limit (Equation (1)) is shown as a black line.

Barrette and others (1999) attributed the increased stiffness to the confining stress, which is proportional to the thickness of the beams and the level of inertial acceleration. The increase in $E$-modulus of saline ice with the level of confinement has been documented elsewhere (Richter-Menge and others, 1986; Gratz, 1996), but it is uncertain why the elastic behavior of freshwater ice is not affected by this parameter to the same extent. The explanation seems likely to be linked to the presence of brine pockets in saline ice, which do not occur in freshwater ice.

\section{MECHANICAL MODEL OF BRINE INCLUSIONS IN SEA ICE}

In this section, a conceptual model of sea ice is constructed based on existing theories of brine inclusions in sea ice. The model is used to qualitatively illustrate the possible existence of the brine-volume transition and freshwater limit, as observed in the modulus measurements.

\section{Stiffness associated with horizontal compression}

While the porosity of freshwater ice is relatively small and may be neglected, saline ice comprises a significant volume of brine pockets. This mosaic of brine-filled voids strongly affects the bulk mechanical properties of sea ice.

Assur (1958) developed a model for the brine-cell geometry of sea ice. Bergdahl (1977) suggested a similar model to explain the variation in the $E$-modulus of sea ice with changes in brine volume. For the simple case of horizontal compression, Bergdahl derived the following relation for bulk elasticity in horizontal compression, $E_{\mathrm{h}}$ based on an idealization of brine-cell structure:

$$
E_{\mathrm{h}}=\frac{E_{\mathrm{i}}}{1-\frac{\left[(1 / K)-E_{\mathrm{i}}\right] v_{\mathrm{b}}}{E_{\mathrm{b}}}},
$$

where

$$
E_{\mathrm{b}}=E_{\mathrm{i}}+\frac{\left[(1 / K)-E_{\mathrm{i}}\right] l_{\mathrm{b}}}{b_{0}},
$$

and where $E_{\mathrm{i}}$ is the elastic modulus of pure ice, $K$ is the compressibility of the brine, $E_{\mathrm{b}}$ is the bulk modulus of the

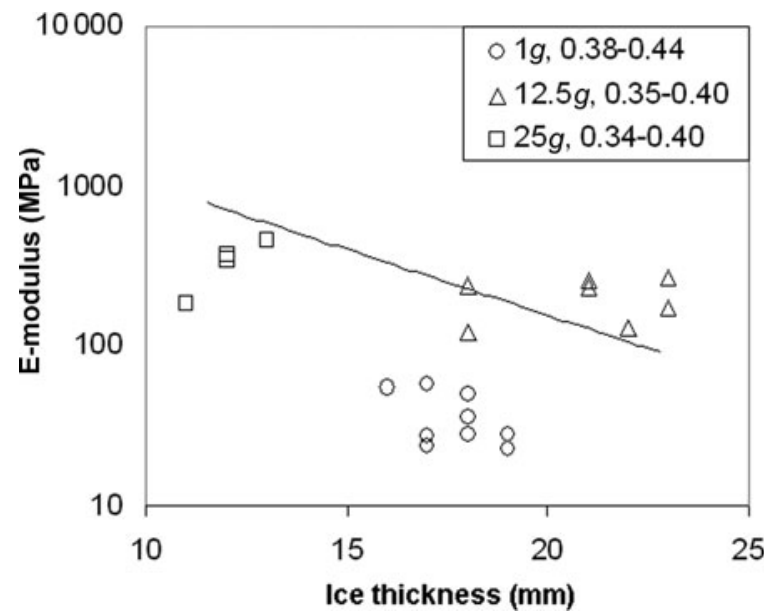

Fig. 7. E-modulus versus ice thickness, $t$, showing the substantial effect of simulated acceleration on $E$ for ice with $v_{b}^{1 / 2}>0.3$ (for actual values see key on figure). The freshwater limit is shown as a black line.

brine layer, $l_{\mathrm{b}}$ is the dimension of the brine voids (assumed square) and $b_{0}$ is the brine-layer thickness.

For brine volumes, $v_{\mathrm{b}}$, up to $10 \%$, Bergdahl (1977) assumed the distance between brine layers, $a_{0}$, was ten times the brine-layer thickness, i.e. $a_{0} / b_{0}=10$. He proposed the relation

$$
\frac{l_{\mathrm{b}}}{b_{0}}=\sqrt{\frac{a_{0}}{b_{0}} v_{\mathrm{b}}}
$$

Bergdahl's model compares well with small-specimen tests by U.P. Langleben and E.R. Pounder (Weeks and Assur, 1967).

For brine volumes greater than $10 \%$, the ice structure consists of unconnected ice plates and rapidly loses its stiffness as the brine is forced out, until the ice platelets come into contact again. For $v_{\mathrm{b}}>10 \%, l_{\mathrm{b}} / b_{0}=1$ and $E_{\mathrm{b}}=1 / K$, the bulk elasticity becomes

$$
E_{\mathrm{h}}=\frac{E_{\mathrm{i}}}{1-\left(1-E_{\mathrm{i}} K\right) v_{\mathrm{b}}} .
$$

\section{Modulus associated with beam flexure}

In this analysis, the ice sheet is modeled as a two-layer construction. The top layer consists of enclosed brine pockets within a solid ice structure. In the bottom layer, the brine pockets are interconnected to form open drainage channels when the brine volume is greater than a critical value. Bergdahl's model was used to calculate the effective modulus for the two layers.

Where $I$ is the moment of inertia of the beam's crosssection, Young (1989) provided the equivalent stiffness, $(E I)_{\text {eq }}$ of the composite system for which the cross-section (dimensions $b \times t$ ) is shown in Figure 8:

$$
(E I)_{\mathrm{eq}}=\frac{b t^{3} r^{3}(1-r) E_{2} E_{1}}{12\left[(1-r) E_{1}+r E_{2}\right]} K_{1}
$$

where $r$ is the ratio of bottom-layer thickness to total thickness, $E_{1}$ and $E_{2}$ are the horizontal modulus of the top and bottom layers, calculated from Equation (5) and the 


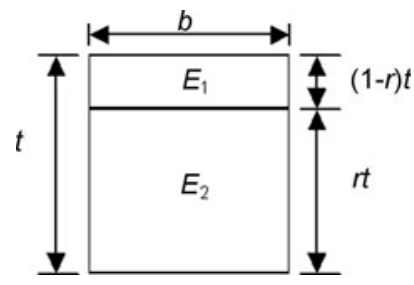

Fig. 8. Idealized diagram of the composite-beam representation of sea ice for calculating its equivalent modulus of elasticity.

value of $K_{1}$ is computed as follows:

$K_{1}=4+6\left(\frac{1-r}{r}\right)+4\left(\frac{1-r}{r}\right)^{2}+\frac{E_{1}}{E_{2}}\left(\frac{1-r}{r}\right)^{3}+\frac{E_{2}}{E_{1}}\left(\frac{r}{1-r}\right)$.

The equivalent modulus, $E_{\text {eq, }}$ of the composite beam is

$$
E_{\mathrm{eq}}=\frac{(E I)_{\mathrm{eq}}}{l} \text {. }
$$

\section{MODEL INPUT VALUES}

The compressibility of brine cavities is greatly influenced by whether they exist as enclosed brine pockets or open drainage channels. Assuming the distance between the brine layers is $0.5 \mathrm{~mm}$ (Nakawo and Sinha, 1982) and drainage channels start to form when the brine pockets are $0.045 \mathrm{~mm}$ thick, i.e. $a_{0} / b_{0}=9$ in Equation (7) (Bergdahl, 1977), the model implies that the ice structure consists of interconnected brine for brine volumes greater than $9 \%$, i.e. $v_{\mathrm{b}}^{1 / 2}>0.3$. Weeks and Ackley (1986) suggest that brinepocket thicknesses of $\sim 0.07 \mathrm{~mm}$ have been measured in natural sea ice. Our slightly different value of $0.045 \mathrm{~mm}$ for brine-pocket thickness is chosen to match the transition observed in the present dataset. When the brine volume of the layer exceeds this critical value, the compressibility is assumed to increase by 20 times and $K$ equals $5.7 \times$ $10^{-11} \mathrm{~Pa}^{-1}$ for air-free water at $5^{\circ} \mathrm{C}$ and normal pressure. The bottom-layer thickness ratio, $r$, is assumed equal to 0.7 times the total thickness.

\section{Relationship of $E$ to $v_{\mathrm{b}}$ in ice in the model}

Figure 9 shows the reduction of $E$-modulus with $v_{\mathrm{b}}$ predicted by the model. The $E$-modulus for different brine volumes is non-dimensionalized by the modulus of pure ice, $E_{\mathrm{i}}$. The measured $E$-modulus values (at $1 g$ ) for the ice-beam thickness of $17.5 \mathrm{~mm}$ are also plotted in the figure. The model predictions illustrate a brine-volume transition as observed in the experimental data.

In the present analysis, the brine cavities are assumed enclosed for $v_{\mathrm{b}}^{1 / 2} \leq 0.3$ and open for $v_{\mathrm{b}}^{1 / 2}>0.3$. For $v_{\mathrm{b}}^{1 / 2}=$ $0.15, E_{\mathrm{eq}} / E_{\mathrm{i}}=0.97$ and for $v_{\mathrm{b}}^{1 / 2}=0.25, E_{\mathrm{eq}} / E_{\mathrm{i}}=0.88$, as computed by the mechanical model. The small variation in $E$ at this range of brine volume is consistent with the negligible influence of brine volume on the $E$-modulus, as shown by the experimental data.

The model predicts a discontinuity at $v_{b}^{1 / 2}=0.3$, where the compressibility, $K$, suddenly increases by 20 times due to the opening of the drainage channels. The amount of drop in $E$ is sensitive to the values of $K$ and $r$. The values of $K$ and $r$ are chosen to match the test results and for illustration purpose only; hence, they can by no means be considered

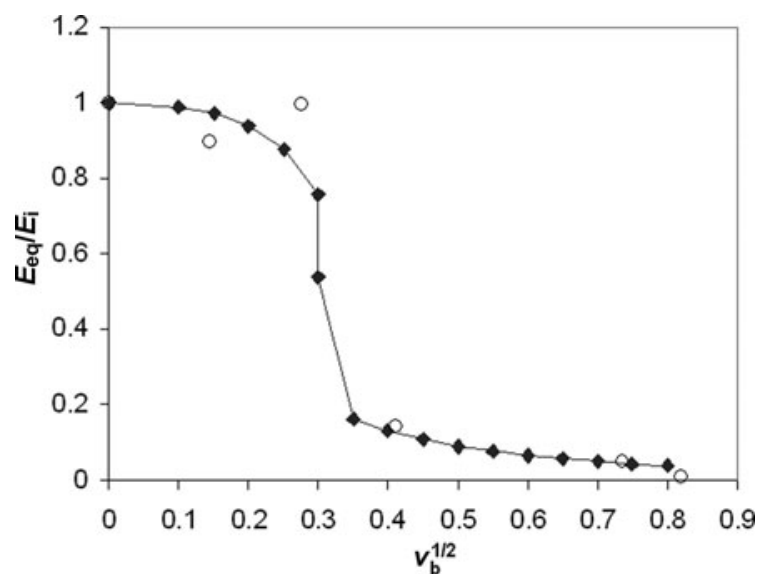

Fig. 9. Non-dimensionalized $E$-modulus versus $v_{b}^{1 / 2}$, showing a comparison between model prediction (solid diamonds and curve) and experimental data (open circles, from Barrette and others, $1999)$ at $1 g$. The $E$-modulus, $E_{\mathrm{eq}}$ at $v_{\mathrm{b}}$ is non-dimensionalized by the $E$-modulus, $E_{\mathrm{o}}$, at $v_{\mathrm{b}}=0$.

expected values. Many factors have not been accounted for in the model, and in particular the causes of low $E$ values measured for this ice are unknown.

\section{Relationship of $E$ to $v_{\mathrm{b}}$ in high-salinity ice in the model}

As mentioned above, the data showed a large increase in $E$-modulus with increased centrifuge acceleration for saline ice $\left(v_{b}^{1 / 2} \sim 0.4\right)$, even with a moderate acceleration of $12 g$. This increase may not be totally accounted for by the effect of beam confinement; other factors may also be at work.

One interesting characteristic of brine-drainage channels is necking just above the ice/water interface. Eide and Martin (1975) give a clear description of this phenomenon. They examined the brine-drainage system in young sea ice and report that the main channel had a diameter of $\sim 1 \mathrm{~cm}$ and the orifice at the neck decreased to a diameter of 2-3 mm. Martin (1974) explained the cause of this necking by considering the balance of two forces acting at the channel entrance. The first is the buoyancy force, $\Delta \rho g$, (created by a density difference, $\Delta \rho$, between the brine and the sea water below the ice cover) that acts upward and opposes the pressure gradient force, $F_{\mathrm{p}}$, which drives the brine out of the ice. Martin (1974) assumed the flow through the neck was Poiseuille flow according to

$$
F_{\mathrm{p}}=\frac{8 \rho_{\mathrm{b}} v_{\mathrm{b}} q}{\pi d^{4}}
$$

where $\rho_{\mathrm{b}}$ is the brine density, $q$ is the volume flux in the neck and $d$ is the radius of the neck. The balance of these two forces determines the equilibrium radius of the neck, i.e.

$$
1=\frac{\pi \Delta \rho n g d^{4}}{8 \rho_{\mathrm{b}} v_{\mathrm{b}} q}
$$

The acceleration scale factor, $n$, is given in the formula to reflect the different rate of centrifugal acceleration. If the other variables are not affected by acceleration, the equation predicts a decrease of neck radius by $n^{1 / 4}$ times, with $n$ as shown in Figure 10. The effect of this necking may decrease the compressibility of the drainage channels, which in turn increases the effective modulus of the beam. Eventually, the drainage channel may be enclosed, with the compressibility approaching that of the enclosed brine pockets. Figure 11 


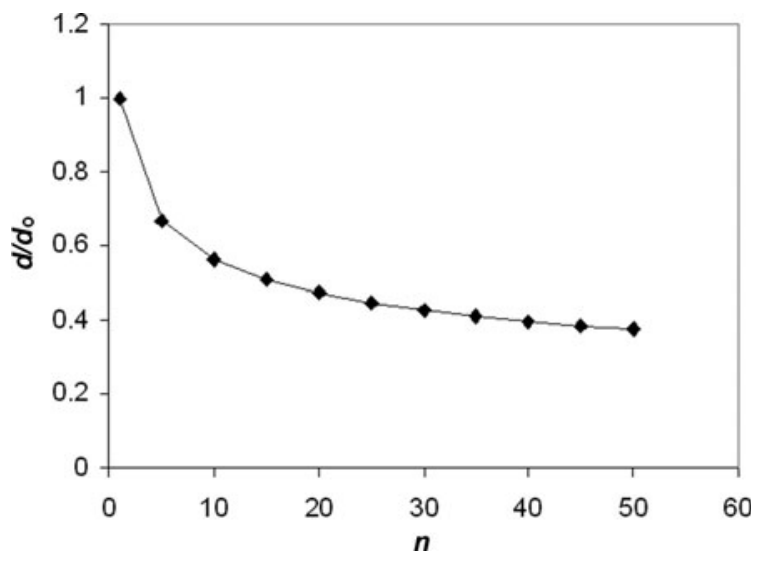

Fig. 10. Non-dimensionalized neck radius versus centrifugal acceleration scale factor, $n$, showing the decrease of neck radius with increasing simulated acceleration. The neck radius, $d$, at $n g$ is nondimensionalized by neck radius, $d_{0}$, at $1 g$.

shows the influence of drainage-channel enclosure on $E$. If the drainage channels were closed due to necking at high acceleration, the increases in $E$ would be of the order of those observed in the experiment. The compressibility of the channels with different neck radius may be calculated using basic fluid-mechanics theories and is not presented here.

\section{CONCLUSIONS}

A re-analysis of Barrette and others' $(1997,1998 b, 1999)$ beam data, taking into account the influence of beam size, shows the influence of brine volume and centrifugal acceleration on the measured values of $E$-modulus that was obscured in the previous analysis. From tests in a centrifuge on small beams at different accelerations, we conclude that only sample size significantly influences $E$-modulus for freshwater ice, with $E$ decreasing as the samples grow larger. However, for saline ice both sample size and centrifugal acceleration have effects dependent on the brine volume. At $1 g$, for saline ice with $v_{b}^{1 / 2}<0.3$, the ice behaved in a similar manner to freshwater ice. At higher accelerations, the $E$-modulus for the saline ice increased and reached a maximum at $25 \mathrm{~g}$. For saline ice with $v_{\mathrm{b}}^{1 / 2}>0.3$, the increase in $E$ with $g$-value was greater for thicker beams than for thinner beams, and at values of $12 g-25 g E$ approached the freshwater limit.

We believe the brine-channel enclosure of saline ice at high centrifugal acceleration is an artifact of the centrifugal test method. This enclosure can explain the large increases in $E$-modulus of saline ice beams tested at high centrifugal accelerations, while predicting negligible increases on freshwater ice beams. The mechanical model of Bergdahl (1977) was extended to a beam-bending configuration and a centrifuge test environment with the provision of brinechannel enclosure at high centrifuge accelerations. The mechanical model developed agrees with the experimental results within reasonable limits.

\section{ACKNOWLEDGEMENTS}

The original experiments were funded by a grant from the Natural Sciences and Engineering Research Council of

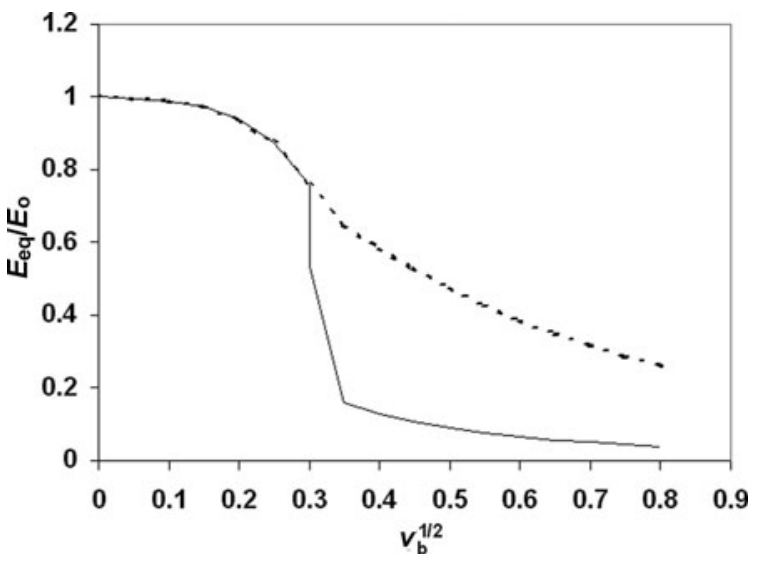

Fig. 11. Non-dimensionalized $E$-modulus versus $v_{b}^{1 / 2}$, showing the influence of drainage-channel enclosure. The lower (solid) curve was computed assuming drainage-channel enclosure at $v_{\mathrm{b}}^{1 / 2} \leq 0.3$. The upper (dashed) curve (limit) is computed assuming the drainage channel was enclosed, i.e. the curve shows the upper limit that can be reached due to drainage-channel enclosure. The $E$-modulus, $E_{\text {eq, }}$ at $v_{\mathrm{b}}$ is non-dimensionalized by the $E$-modulus, $E_{\mathrm{o}}$, at $v_{\mathrm{b}}=0$.

Canada. M. Lange was the scientific editor. W.F. Weeks and J. Richter-Menge reviewed the paper. Their valuable comments on the manuscript are gratefully acknowledged.

\section{REFERENCES}

Assur, A. 1958. Composition of sea ice and its tensile strength. In Arctic Sea Ice, Conference, Easton, Maryland, February 2427, 1958, Proceedings. Washington, DC, US National Academy of Sciences, 106-138. (National Research Council Publication 598.)

Barrette, P.D. 1997. Cantilever beam testing of freshwater ice in a centrifuge. In Proceedings of the 16th International Conference on Offshore, Mechanics and Arctic Engineering, 13-17 April 1997, Yokahoma, Japan, Vol. 4. New York, American Society of Mechanical Engineers, 407-413.

Barrette, P.D., R. Phillips, J.I. Clark, G. Crocker and S.J. Jones. 1998a. Mechanical testing of floating ice sheets. In Proceedings of the International Conference Centrifuge'98, 23-25 September 1998, Tokyo, Japan. Rotterdam, etc., A.A. Balkema, 881-886.

Barrette, P.D., R. Phillips, J.I. Clark, G. Crocker and S.J. Jones. 1998 b. Physical properties of columnar ice grown in a centrifuge. In Proceedings of the 17th International Conference on Offshore Mechanics and Arctic Engineering, 5-7 July 1998, Lisbon, Portugal. Vol. 2. New York, American Society of Mechanical Engineers, 519-525.

Barrette, P.D., R. Phillips, J.I. Clark, G. Crocker and S.J. Jones. 1999. Flexural behavior of model sea ice in a centrifuge. J. Cold Reg. Eng., 13(3), 122-138.

Bergdahl, L. 1977. Physics of ice and snow as affects thermal pressure. Göteborg, Chalmers University of Technology, Department of Hydraulics. (Report Series A:1, 158.)

Clough, H.F. and T.S. Vinson. 1986a. Ice forces on fixed conical structures. In Proceedings of the 5th International Offshore Mechanics and Arctic Engineering Symposium, April 1986, Tokyo, Japan. New York, American Society of Mechanical Engineers, 507-514.

Clough, H.F. and T.S. Vinson. 1986b. Centrifuge model experiments to determine ice forces on vertical cylindrical structures. Cold Reg. Sci. Technol., 12(3), 245-259.

Eide, L.I. and S. Martin. 1975. The formation of brine drainage features in young sea ice. J. Glaciol., 14(70), 137-154. 
Gagnon, R.E. and S.J. Jones. 2001. Elastic properties of ice. In Levy, M., H. Bass and R. Stern, eds. Handbook of elastic properties of solids, liquids and gases. Vol. 3. New York, Academic Press, 229-257.

Golden, K.M. 2001. Brine percolation and the transport properties of sea ice. Ann. Glaciol., 33, 28-36.

Golden, K.M., S.F. Ackley and V.I. Lytle. 1998. The percolation phase transition in sea ice. Science, 282(5397), 2238-2241.

Gratz, E.T. 1996. Brittle failure of columnar S2 ice under triaxial compression. (PhD thesis, Dartmouth College.)

Langhorne, P.J., K.J.L. Stone and C.C. Smith. 1999. The bearing capacity of saline ice sheets: centrifugal modelling. Can. Geotech. J., 36(3), 467-481.

Lau, M., R. Phillips, R.F. McKenna and S.J. Jones. 2001. Size effect on the flexural strength of ice in model testing. In Frederking, R., I. Kubat and G. Timco, eds. Proceedings of the 16th International Conference on Port and Ocean Engineering under Arctic Conditions, 12-17 August 2001, Ottawa, Canada. Vol. 3. Ottawa, Ont., Canadian Hydraulics Centre, 1413-1423.

Lovell, M. and A.N. Schofield. 1986. Centrifugal modelling of sea ice. In Murthy, T.K.S., J.J. Connor and C.A. Brebbia, eds. Proceedings of the First International Conference on Ice Technology, June 1986, Cambridge, Massachusetts. Berlin, Springer-Verlag, 105-113.

Martin, S. 1974. Ice stalactites: comparison of a laminar flow theory with experiment. J. Fluid Mech., 63, Part 1, 51-79.
Murff, J.D. 1996. The geotechnical centrifuge in offshore engineering. In Geology, Earth Sciences and Environmental Factors: Proceedings of the International Offshore Technology Conference, 6-9 May 1996, Houston, Texas, Vol. 1. Houston, TX, Offshore Technology Conference, 675-689.

Nakawo, M. and N.K. Sinha. 1982. A note on the brine layer spacing of first-year ice. Atmos.-Ocean, 22(2), 193-206.

Parsons, B.L. and 7 others. 1992. The influence of beam size on the flexural strength of sea ice, freshwater ice, and iceberg ice. Philos. Mag. A, 66(6), 1017-1036.

Richter-Menge, J.A., G.F.N. Cox, N. Perron, G. Durell, and H.W. Bosworth. 1986. Triaxial testing of first-year sea ice. CRREL Rep. 86-16.

Schofield, A.N. 1980. Cambridge geotechnical centrifuge operations. Géotechnique, 30(3), 227-269.

Schwarz, J. and 7 others. 1981. Standardized testing methods for measuring the mechanical properties of ice. Cold Reg. Sci. Technol., 4(3), 245-253.

Weeks, W.F. and A. Assur. 1967. The mechanical properties of sea ice. CRREL Monogr. II-C3.

Weeks, W.F. and S.F. Ackley. 1986. The growth, structure, and properties of sea ice. In Untersteiner, N., ed. Geophysics of sea ice. London, etc., Plenum Press, 9-164. (NATO ASI Series B: Physics 146.)

Young, W.C. 1989. Roark's formulas for stress and strain. Sixth edition. New York, McGraw-Hill.

MS received 29 November 2006 and accepted in revised form 3 March 2008 